\title{
Erratum to: Evaluating optical measurements of leaf area index against litter collection in a mixed broadleaved-Korean pine forest in China
}

Zhili Liu · Guangze Jin $\cdot$ Jing M. Chen ·

Yujiao Qi

Published online: 25 October 2014

(C) Springer-Verlag Berlin Heidelberg 2014

Erratum to: Trees

DOI 10.1007/s00468-014-1058-2

The RMSE values in Figs. 3-8 were erroneously pub-

lished. The corrected figures are given below:

The online version of the original article can be found under doi:10.1007/s00468-014-1058-2.

Z. Liu · G. Jin $(\bowtie)$

Center for Ecological Research, Northeast Forestry University,

Harbin 150040, China

e-mail: taxus@126.com

Z. Liu

e-mail: liuz12093@126.com

J. M. Chen

Department of Geography, University of Toronto, Toronto,

ON M5S 3G3, Canada

e-mail: chenj@geog.utoronto.ca

Y. Qi

School of Forestry, Northeast Forestry University,

Harbin 150040, China

e-mail: 297148363@qq.com 
Fig. 3 Relationship between LAI estimated by litter collection $\left(\mathrm{LAI}_{\text {lit }}\right)$ and effective LAI from DHP with different zenith angle ranges. The dotted line indicates the $1: 1$ relationship

Fig. 4 Relationship between LAI estimated by litter collection $\left(\mathrm{LAI}_{\text {lit }}\right)$ and effective LAI from DHP after correcting for the woody-to-total area ratio $(\mathrm{W})$, clumping index $(\mathrm{C})$ and needle-to-shoot area ratio (N) $\left(\mathrm{LAI}_{\text {DHP-WCN }}\right)$ according to Eq. (1) with different zenith angle ranges. The dotted line indicates the 1:1 relationship
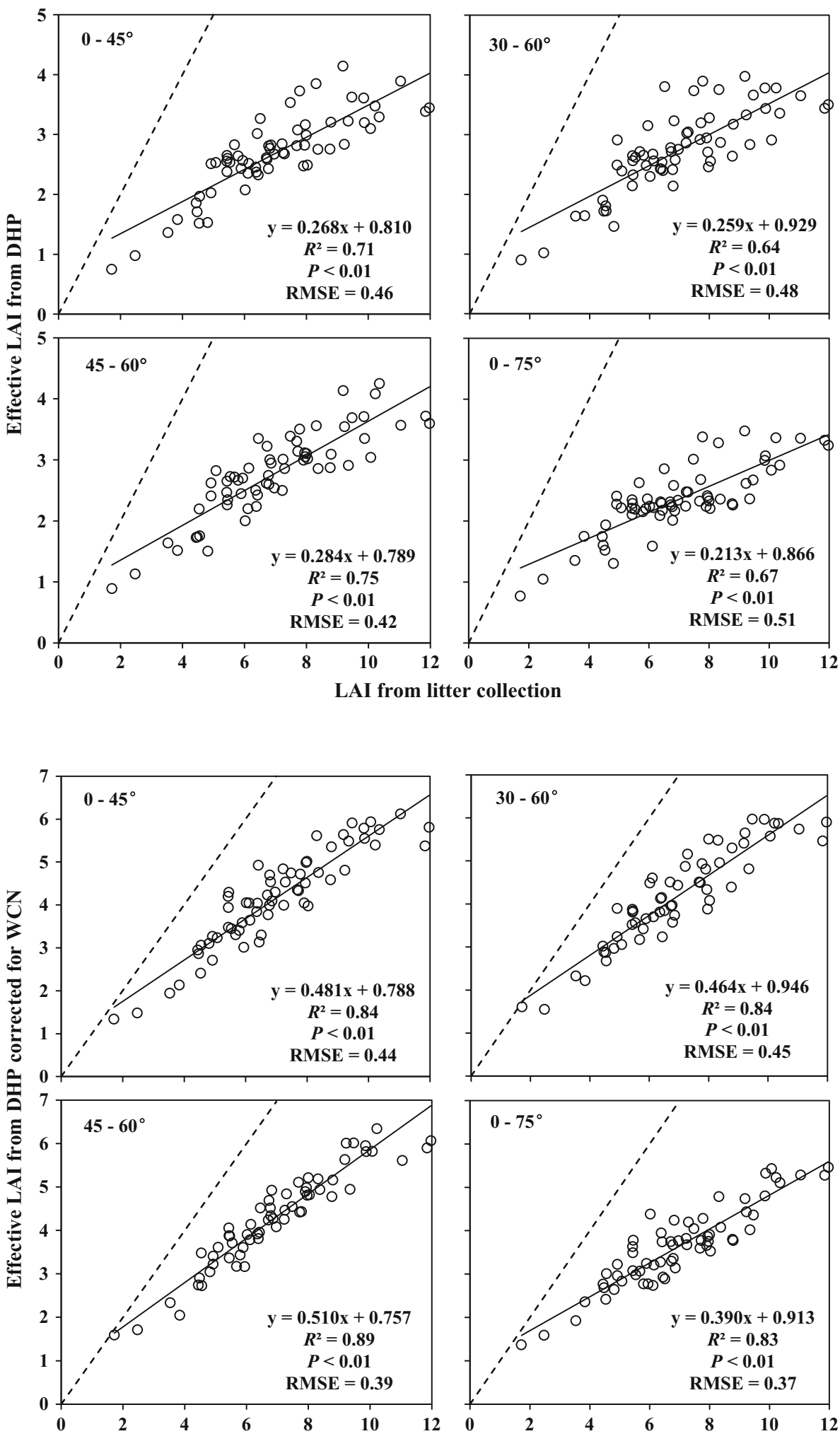

LAI from litter collection 
Fig. 5 Relationship between LAI estimated by litter collection $\left(\mathrm{LAI}_{\text {lit }}\right)$ and effective LAI from DHP after correcting for the automatic exposure with different zenith angle ranges. The dotted line indicates the 1:1 relationship

Fig. 6 Relationship between LAI estimated by litter collection $\left(\mathrm{LAI}_{\text {lit }}\right)$ and effective LAI from DHP after correcting for the woody-to-total area ratio $(\mathrm{W})$, clumping index $(\mathrm{C})$ and needle-to-shoot area ratio (N) and automatic exposure (E) $\left(\mathrm{LAI}_{\text {DHP-WCNE }}\right)$ with different zenith angle ranges. The dotted line indicates the 1:1 relationship
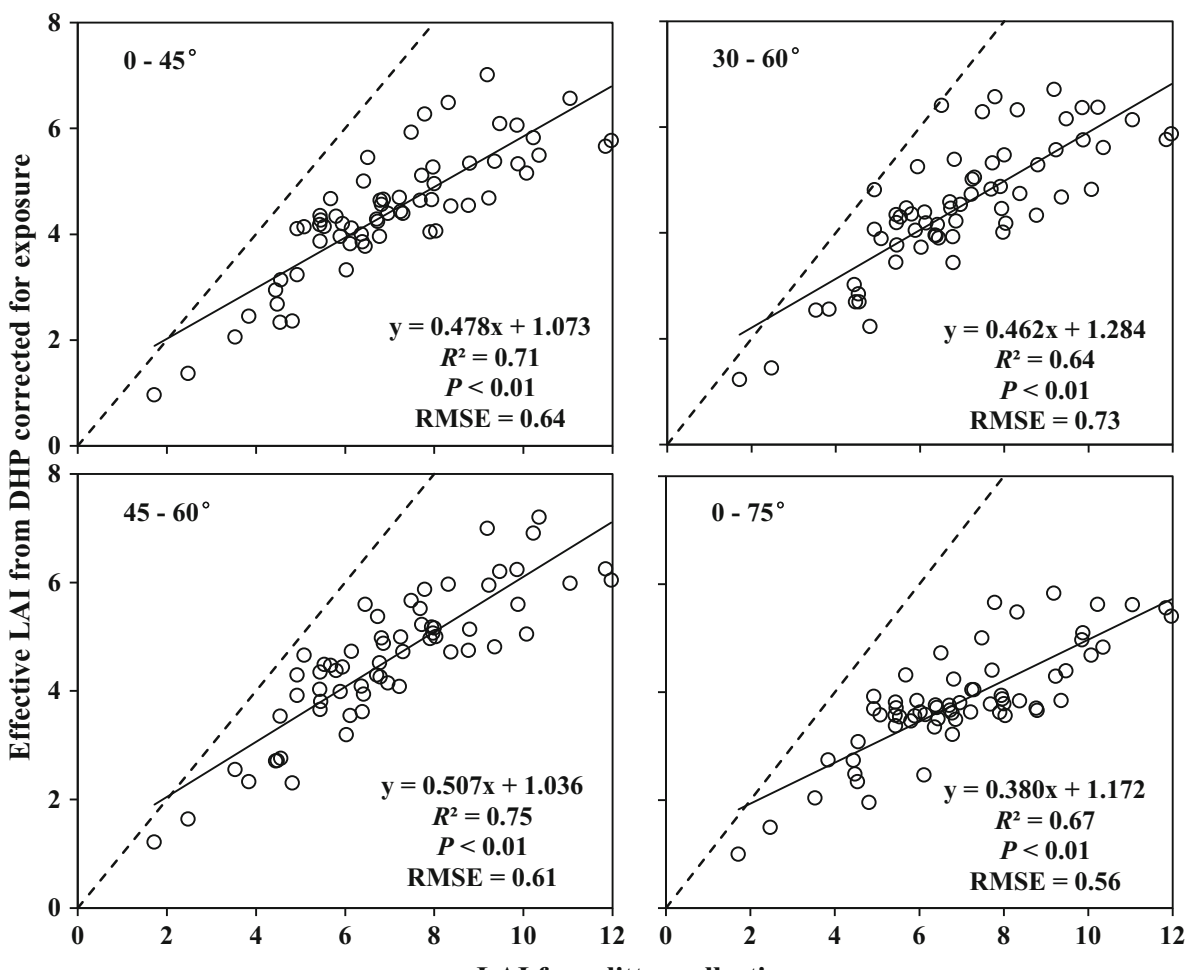

LAI from litter collection
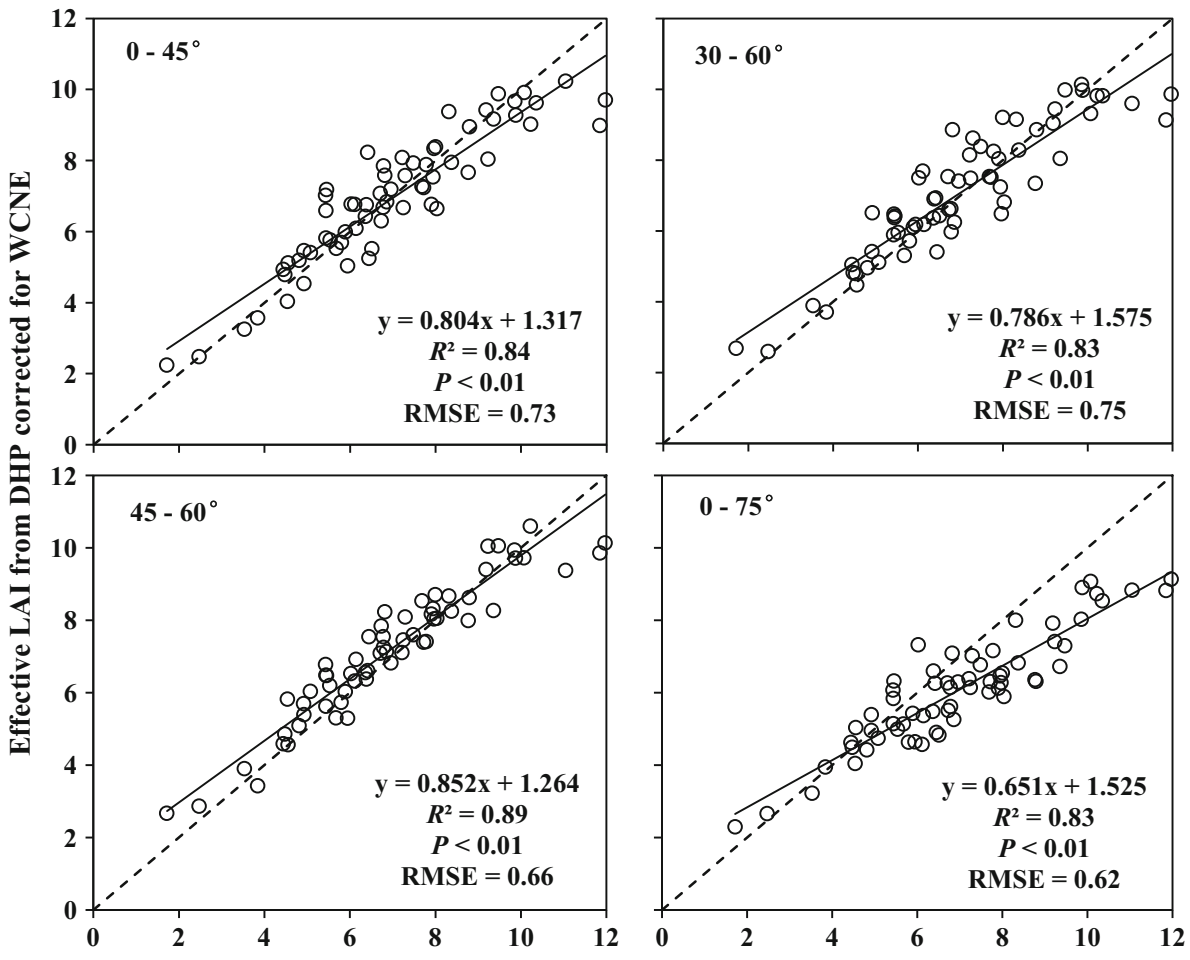
Fig. 7 Relationship between LAI estimated by litter collection $\left(\mathrm{LAI}_{\text {lit }}\right)$ and effective LAI from LAI-2000 with different zenith angle ranges. The dotted line indicates the 1:1 relationship

Fig. 8 Relationship between LAI estimated by litter collection $\left(\mathrm{LAI}_{\text {lit }}\right)$ and effective LAI from LAI-2000 after correcting for the woody-tototal area ratio $(\mathrm{W})$, clumping index (C) and needle-to-shoot area ratio $(\mathrm{N})\left(\mathrm{LAI}_{2000-\mathrm{wCN}}\right)$ according to Eq. (1) with different zenith angle ranges.

The dotted line indicates the 1:1 relationship
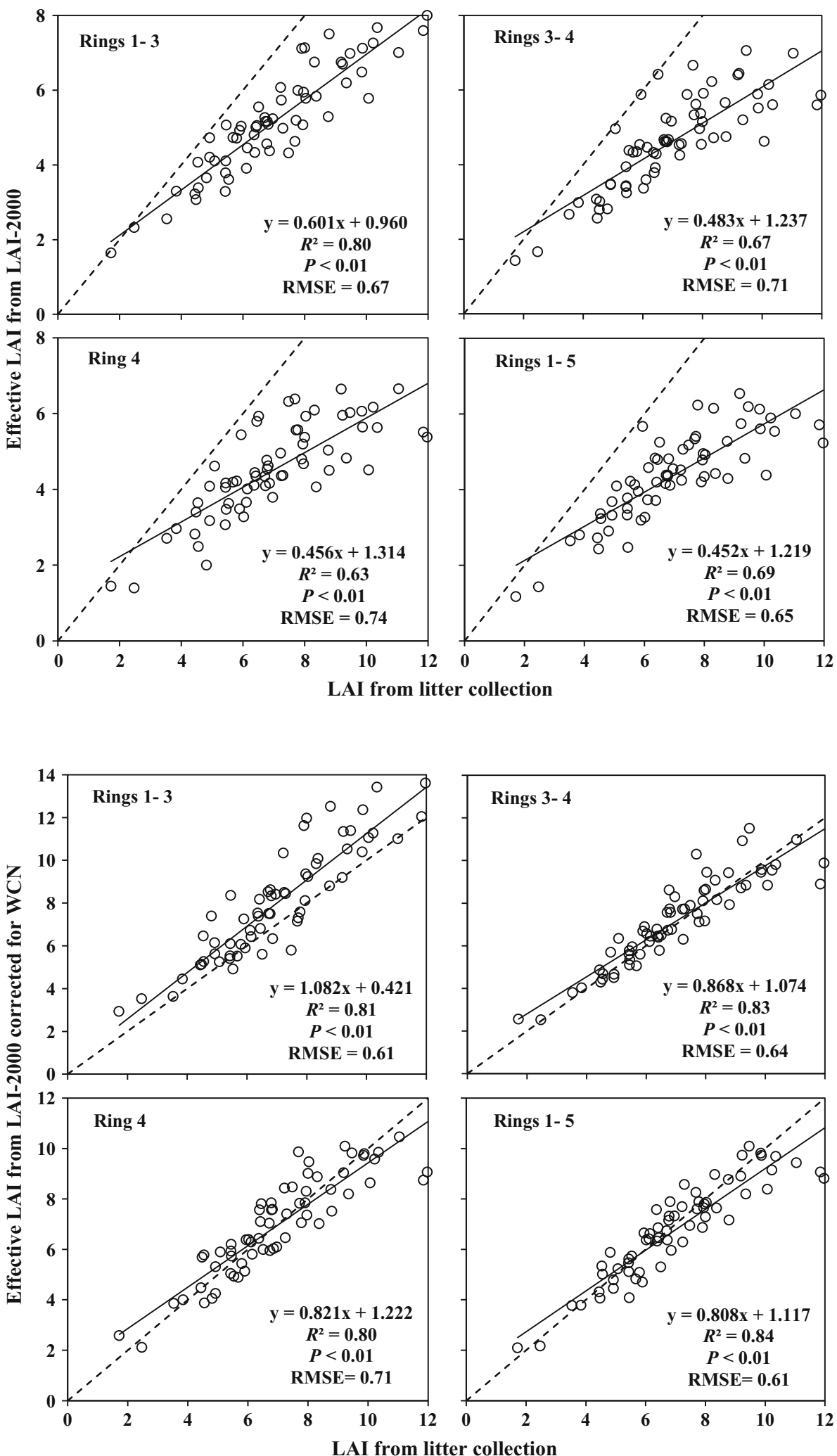